\title{
UNA CARTA INÉDITA DE FRANCISCO JAVIER CLAVIJERO, EN TORNO A LA SUPRESIÓN DE LA COMPAÑía DE JESÚS
}

\author{
RINALDO FROLDI \\ Università di Bologna \\ Al colega y amigo, destacado iberoamericanista, \\ Giuseppe Bellini, con estima y afecto.
}

Del autor de la Storia antica del Messico ${ }^{1}$, se conservan en la Biblioteca Estense de Módena dos manuscritos ${ }^{2}$, que hablan de la supresión de la Compañía ${ }^{3}$ pese a la prohibición impuesta a los ex-jesuitas de escribir en torno a este tema.

El primer manuscrito es un discurso pronunciado ante la hermandad antes de que su supresión hubiese sido decidida: revela la angustia de la espera ante un evento considerado trágico para la Compañía y para la suerte misma de la Iglesia y suena más a una exhortación a los hermanos para que sean fuertes en dicha dolorosa circunstancia que una invitación a la frágil esperanza de que este evento no se cumpla. Al mismo tiempo se reafirma la devoción total a Cristo a quien, al igual que le está sucediendo a la Compañía, lo persiguieron y fue condenado a muerte, y con quien comparten la inquebrantable creencia de una Fe superior a cualquier persecución «o vivamos o muramos, o perezca la Compañía, siempre somos del Señor ...» (vid. n. 12).

El segundo manuscrito (que publicamos aquí) ${ }^{4}$, es el texto de una car-

\footnotetext{
${ }^{1}$ Francisco Xavier Clavigero, Storia antica del Messico, 3 vol., más uno de Dissertazioni, Gregorio Biasini, Cesena, 1780-81.

${ }^{2}$ Se trata de los mss. del Fondo Sorbelli, con signatura Ms. 193 y Ms. 187. Éstos son descritos brevemente en la p. $95, \mathrm{n}$. 70 de la biografía más amplia y documentada existente de P.Clavijero: Charles E. RonAN, S. J., Francisco Javier Clavigero S. J (17311787) Figure of the mexican Enlightenment: his Life and Works, Institutum Historicum, Roma-Loyola University Press, Chicago, 1977.

${ }^{3}$ La supresión fue decretada por el Papa Clemente XIV con el breve Dominus ac Redemptor, con fecha del 21 de julio de 1773.

${ }^{4}$ Ms. 187 de la Biblioteca Estense de Módena, catalogado con el título: «Carta sobre el juicio que formará la posteridad sobre la destrucción de los jesuitas». Agradezco al Director de la Biblioteca, dott. Ernesto Milano, por haber autorizado la publicación.
} 
ta dirigida a un anónimo corresponsal extranjero ${ }^{5}$, presumiblemente escrita en 1776 o poco después ${ }^{6}$.

Reflexionando sobre la ya entonces consumada supresión de la Compañía, Clavijero se pregunta cuál será el juicio que merecerán los actores desta tragedia en el futuro.

Se trata de un texto que defiende con ahínco a la Compañía, y se muestra amargamente polémico por lo que considera que fue una operación sustancialmente política. Severo es el veredicto de condena que da a los soberanos que lo impusieron, y todavía más violenta es la execración del Pontífice ${ }^{7}$, por su condescendencia culpable.

Clavijero considera una verdadera injusticia la persecución que se produjo contra los Jesuitas: ésta le trae el recuerdo, como atento observador de la historia, de otra célebre persecución padecida por otra Orden religiosa, los Templarios, acaecida al inicio del siglo $\mathrm{XIV}^{8}$.

${ }^{5}$ Clavijero se refiere a él con el título abreviado de Mr. (abreviación que en español correspondería bien al francés «Monsieur», o bien al inglés «Mister»). Aunque el anónimo destinatario podría ser también ficticio.

${ }^{6}$ RonAN, op. cit., la atribuye a «sometime after 1775». En efecto, en la carta se señala la muerte del Padre general de los Jesuitas, Lorenzo Ricci, prisionero en el Castel Sant' Angelo, cuya vida se apagó el 24 de noviembre de 1775 (véase adelante n. 10).

${ }^{7}$ Clemente XIV, nacido como Giovan Antonio Ganganelli (1705), de Sant' Arcangelo di Romagna, había profesado como franciscano en 1724. Llegó a ser consejero del Santo Oficio en 1745 y cardenal en 1759. Fue elegido Papa en 1769 tras un largo cónclave en el cual resultó decisiva la aportación del grupo de los cardenales cercanos a las Cortes borbónicas, hasta el punto de que nació la sospecha de que Ganganelli hubiese pactado con éstos la tiara bajo la promesa de suprimir la Compañía de Jesús. La supresión (1773) fue decretada después de un largo período de incertezas y de dudas por parte del Pontífice, bajo la presión, cada vez más fuerte, de las Cortes borbónicas, en especial de la Corte española. Hacemos notar que después de Clemente XIV, ningún otro Papa ha asumido el nombre de Clemente.

Sobre la extinción de la Compañía de Jesús, consultar:

A. THEINER, Histoire du pontificat de Clément XIV, París, 1852, 2 vol.; trad. it. Milán, 1885; F. MASson, Le Cardinal De Bernis depuis son ministère (1758 - 1794). La suppression des jésuites, Paris, 1884; G. C. CORDARA, De supressione Societatis Jesu Commentarii, ed. a cura di G.Albertotti, Padova, 1925; E. RosA, I Gesuiti dalle origini ai giorni nostri, Roma, 1930; L. VON PASTOR, Storia dei Papi, Roma, 1933, vol. XVI, n. 2; M. BATLLORI, Entre la supresión y la restauración de la Compañía de Jesús, 17731814 , en «Arch. hist. Soc. Jesu, XLIII, 1974, pp. 364-393; F. VENTURI, Settecento riformatore, Turín, 1976, II, 326-342.

${ }^{8}$ La orden militar-caballeresca de los Templarios fue fundada alrededor de 1120 con la finalidad de proteger a los católicos en Jerusalén (el «Templo») y fue ratificada por el Papa Onorio II en 1128. Los Templarios, obligados a dejar el Oriente, de modo paulatino, por las continuas presiones de los sarracenos, se retiraron a Occidente, donde la orden prosperó hasta suscitar la envidia de muchos, comenzando por Felipe IV, el Hermoso, rey de Francia de 1285 a 1314. Éste obligó al débil Papa Clemente V (estamos en el período del traslado de la Corte papal a Aviñon) a extinguir en 1312 la Orden, bajo la acusación de herejía, así como del prácticas mágicas y perversas, pese a la opi- 
A distancia de cuatro siglos, sostiene Clavijero: nosotros, jueces imparciales, no perturbados por las pasiones del momento, hemos llegado a reconocer y a condenar a los perseguidores y exterminadores de los Templarios, el ávido Rey Felipe IV, el Hermoso, y el simoníaco Papa Clemente $V$.

De igual modo, a distancia de otros cuatro siglos, la posteridad podrá juzgar con objetividad los acontecimientos presentes. Su imaginación lo lleva a imaginar cuál sería este juicio.

Para Clavijero, su siglo no será considerado ciertamente como el siglo de las luces y de la humanidad, como, con demasiada insistencia, sus contemporáneos han sostenido y sostienen, sino que lo juzgarán cargado de errores filosóficos y morales: entre éstos, aparecerán como gravísimas las persecuciones de los Jesuitas en Portugal, Francia, España y en los restantes países dirigidos por Cortes borbónicas ${ }^{9}$.

Igualmente reprobable aparecerá el comportamiento del Papa Clemente XIV porque Clavijero retiene, en conformidad con las voces ampliamente difundidas en su tiempo, que había obtenido el Papado a través de un acuerdo secreto con los jansenistas, enemigos acérrimos de los Jesuitas, y con los cardenales más cercanos a los Borbones, españoles y franceses sobre todo, bajo promesa hecha de eliminar la Orden una vez elegido.

Clavijero se adhiere además a la extendida creencia popular de una profecía según la cual el Pontífice simoníaco moriría antes de que se celebrase el Jubileo que había convocado para el año 1775. En efecto, murió el 22 de septiembre de 1774 (y Clavijero subraya los pormenores de su muerte miserable y de la rápida descomposición de su cuerpo, rechaza la

nión del Concilio eclesiástico general reunido en Viena en 1311. Recuérdese la severa condena que pronunció Dante contra Felipe el Hermoso y Clemente V (Infierno, XIX, 82-87 y Purgatorio XX, 91-93).

De la vasta bibliografía sobre los Templarios, señalo algunas voces fundamentales:

F. E. LEWIS, Story of the Knights Templars (1118-1315), 1934; G. A. CAMPBELL, Knights Templars. Their Rise and Fall, 1938; J. H. PROBST-BIRABEN, Les Mystères des Templiers, Niza, 1947; J. CHARPENTIER, L'Ordre des Templiers, París, 1962; G. LEGMAN, The Guilt of the Templars, New York, 1966; M. BARBER, The Trial of the Templars, Cambridge, 1978; P. PARTNER, The murdered magicians: the Templars and their Myth, Oxford, 1978, trad.it. I Templari, Turín, 1991.

${ }^{9}$ Los Jesuitas fueron expulsados de Portugal el 3 de septiembre de 1759, por iniciativa del Primer Ministro, Sebastiâo José de Carvalho, Marqués de Pombal: entre los motivos de la expulsión está la acusación a los Jesuitas de haber participado en la conjura del 3 de septiembre de 1758 para suprimir al Rey Giuseppe Emanuele I.

En Francia, la supresión de la Compañía, querida con gran empeño por parte de la favorita del Rey, la Marquesa de Pompadour, fue decretada por Luis XV, en el edicto del 1 de diciembre de 1764.

En España, Carlos III deliberó la expulsión de los Jesuitas de todos los territorios de la Corona con un decreto del 27 de febrero de 1767. Con análogos decretos, los Jesuitas fueron expulsados en 1768 de Parma y del Reino de las dos Sicilias. 
insinuación jansenista de que hubiera sido envenenado por los Jesuitas, y propende a la interpretación generalizada en el pueblo de Roma de que se debiera al brazo del justo castigo divino.

No deja de marcar la extrema crueldad con la que han sido tratados muchos de los numerosos inocentes hechos prisioneros y procesados por delitos inexistentes, como el General de la Orden, Lorenzo Ricci, encerrado en Castel Sant'Angelo hasta el día de su muerte ${ }^{10}$.

Además, como clamoroso sello de la injusticia consumada, la posteridad no podrá ignorar la paradójica circunstancia de que la protección y conservación de la Orden provenga, precisamente, de dos soberanos «herejes», Federico de Prusia y Catalina de Rusia, quienes no quisieron publicar el breve pontifical y aceptaron a la Compañía de Jesús en sus reinos, ya sea porque no les resultaran claros los motivos de su supresión, ya sea porque no quisieron privar a sus súbditos católicos de una educación religiosa y una formación cultural, que los Colegios jesuitas habían demostrado saber impartir ${ }^{11}$ mejor que cualquier otra Orden.

La carta termina con la negación de la esperanza de un restablecimiento de la Compañía y con la convencida afirmación de una segura futura condena moral de los culpables: Clavijero sostiene que no ha pretendido actuar como profeta, sino que se trata de los posibles resultados históricos de un análisis de los hechos presentes llevado a cabo a la manera en que se juzga el pasado.

En el texto de Clavijero emerge una enorme dosis de humanidad: sin abandonar su habitual actitud reflexiva, el autor deja traslucir una apasionada participación en el doloroso acontecimiento que le induce a pronunciar una condena moral contundente de una actuación que considera enormemente injusta.

Hay una profunda amargura al meditar sobre lo acontecido que imposibilita la esperanza de un futuro restablecimiento de la Orden. Tampoco se ven indicios de ese resignado abandono a la inescrutable voluntad divi-

${ }^{10}$ Lorenzo Ricci (nacido en Florencia en 1703, jesuita desde 1718, profesó en 1736; desde 1755 secretario general) fue elegido en 1758 Preboste general de la Orden. En el acto de la supresión de la Compañía fue arrestado y estuvo prisionero, primero en el Colegio inglés (16-8-1773), y después desde el 23-9-1773 en Castel Sant'Angelo, acusado de haber escondido en el extranjero muchos bienes de la Compañía, acusación que jamás fue demostrada. Bajo la presión de las Cortes borbónicas permaneció prisionero tras la muerte de Clemente XIV bajo el pontificio de Pío VI, hasta que murió el 24 de noviembre de 1775 , dejando manifestado por escrito su inocencia y la de la entera Compañía.

${ }^{11}$ Los Colegios jesuitas existieron en Prusia hasta el 1780; en Rusia incluso más. Pío VI, verbalmente permitió su supervivencia, y Pío VII, con un breve del 7 de marzo de 1801, aprobó oficialmente la existencia de la Compañía en el Imperio ruso. El 30 de julio de 1804 la aprobación se extendió al Reino de las dos Sicilias, y el 7 de agosto de 1814, Pío VII restableció a la Compañía en su forma original. 
na que, en el discurso a la hermandad poco antes de su desaparición le había hecho decir: Reflexionemos atentamente en la presencia divina que si la Compañía se acaba es porque Dios su autor y fin ya no quiere usar de ella: acaso querrá excitar en su lugar otra Religión más perfecta ... Si el amor que profesamos a la Compañía es, como debe ser, bien ordenado, debemos prontamente sacrificarlo a la voluntad del Señor, adorando y respetando los infalibles secretos de la Providencia ${ }^{12}$.

En la carta reafirma orgullosamente su fidelidad a la profesión religiosa, en su tiempo hecha, y la firme conciencia de que los Jesuitas, representantes de Cristo en la tierra, no han traicionado jamás la regla de San Ignacio. Clavijero llega a admitir los errores cometidos por algunos de los hermanos (cierta soberbia intelectual, en especial cuando se trataba de otras Órdenes religiosas, la audacia de algunas tesis teológicas, cierto exceso de laxitud moral), culpas que en ningún, caso justifican la persecución de la entera Orden.

Con acalorada emoción el discurso se enciende en interrogaciones dirigidas al destinatario de la carta, que sirven, sustancialmente, a una afirmación más categórica de las ideas del autor. Además de estas interrogaciones retóricas, se sirve a menudo de vivaces exclamaciones con clara intencionalidad persuasora. Estos recursos formales encuentran un feliz equilibrio en la linealidad de su razonamiento de fondo lógico y coherente. El ápice del discurso elocuente aparece cuando el autor apostrofa directamente al Papa, gritándole su protesta y su condena de aquellos a los que retiene como personas de culpable comportamiento y de debilidades imperdonables.

En cuanto al pensamiento que sostiene todo el escrito, parece coherente con la ideología de Clavijero, tal y como aparece en sus grandes obras históricas: la Storia antica del Messico y la Storia della California ${ }^{13}$.

\footnotetext{
${ }_{12}$ Ms. 193 de la Biblioteca Estense de Módena, catalogado con el título: «Discorso tenuto dal P.Clavijero ai suoi compagni del Messico dopo la sospensione e innanzi di sbadarse per le varie parti del mondo», f.4. Me propongo publicar también este ms. inédito próximamente.

${ }^{13}$ Historia de la California, editada póstumamente, a Venecia, a través de M. Fenzo, 1789 , dos volúmenes en uno.

Sobre la amplia bibliografía crítica sobre la vida y obra de Clavijero, cito sólo alguno de los más recientes trabajos que considero fundamentales (además de la ya citada en la nota 2, obra de RONAN): M. LEÓN PORTILla, Recordación de Francisco Xavier Clavijero. Su vida y su obra, Veracruz, 1970 (reproducido como Presentación de la edición de la Historia Antigua de México (facs. de la ed. Ackermann de 1826), Xalapa, 1985; Jesús GÓMEZ FRAGOSO, Clavigero, ensayo de interpretación y aportaciones para su estudio, Guadalajara, 1979; Giovanni MARCHETTI, Cultura indigena e integrazione nazionale. La "Storia antica del Messico» di F. J.Clavijero, Abano Terme, 1980, (existe trad. en español: Cultura indígena e integración nacional. La «Historia antigua de México» de F. J. Clavijero, Xalapa, 1986; Francisco Xavier Clavigero en la Ilustración mexicana, 1731-1787 (ed. Alfonso Martínez Rosales), El Colegio de México, 1988.
} 
Conservándose siempre fiel a una severa ortodoxia, se mostró predispuesto a acoger del pensamiento moderno todo lo que no contradijera los principios fundamentales del catolicismo. Así, las nuevas ciencias podían ser aceptadas con tal de que no pretendieran negar la supremacía de la teología. Pudo, de este modo, en el campo de la historiografía, obtener indiscutibles éxitos científicos, aunque restase ligado a una visión agustiniana del proceso histórico ${ }^{14}$

En este sentido Clavijero participó —en el período de la Ilustraciónen el movimiento renovador del pensamiento cristiano, definido por algunos con el término Iluminismo cristiano ${ }^{15}$, término contradictorio en sí mismo y - para nosotros - poco apropiado. Su planteamiento coincidía con el de tantos otros hermanos, pero él fue un opositor particularmente violento y polémico de la Ilustración más radical. También en la carta hay alguna evidencia de sus convicciones profundas: su condena absoluta del pensamiento de Voltaire y de Rousseau, considerados como malos maestros, como los que han contribuido a formar el retrato de nuestro siglo, secularizado y fuertemente crítico de la tradición cristiana, y en particular de la católica. Igualmente firme es la condena de cualquier forma emergente de materialismo y, en materia política, la reprobación — para él, realista convencido y defensor de la aristocracia - de la apertura democrática de los Parlamentos, guiada por los jansenistas y por los philosophes, y de cualquier forma de galicanismo y, en fin, la inexorable condena de los jansenistas. Naturalmente la condena se extiende a todos los que han pactado con las nuevas ideas subversivas y no han tenido la fuerza de oponerse. Precisamente por la firmeza en las creencias tradicionales, él sabe que los Jesuitas han atraído el odio de tantos, pero está convencido de que, precisamente, su firme oposición a cualquier forma de herejía y la renuncia al compromiso, juzgado por el mundo como una culpa, constituyen un motivo de elogio.

En la encarcelación de los Jesuitas (el espectáculo de Jesucristo llevado violentamente en medio de corchetes) y en su condena injustificada y sostenida por falsos argumentos, en la destrucción de la Compañía, ve el inicio de un período de decadencia de la Iglesia, aunque no el inicio de un proceso de extinción (la Santa Sede ... que infaliblemente subsistirá en todos tiempos a pesar de las faltas de sus Pontífices y de todos los esfuerzos de sus enemigos).

Sostenemos que dar a conocer este manuscrito inédito contribuirá a precisar el carácter fiero de Clavijero, irreductible Jesuita, firme sostenedor de sus ideas hasta llegar al rechazo riguroso de las ideas de los demás, pero indudablemente personalidad íntegra y de rica humanidad.

${ }^{14}$ G. MARCHETTI, op. cit., pp. 94-95 y 97-101.

15 Vid. Ch. RonAN, op.cit., pp. 19 y 20 y nota 52. 


\section{CARTA DE N. SOBRE EL JUICIO QUE FORMARÁ LA POSTERIDAD DE LA DESTRUCCIÓN DE LOS JESUITAS ${ }^{16}$}

¿Qué os parece Mr. que pensarán los siglos venideros de la destrucción de la Compañía? Ellos sin duda hablarán sin respeto ni temor de los actores desta tragedia, condenarán sin piedad no solamente a los Jesuitas, si lo creyeren culpados, sino al mismo Papa, y a cada uno de los Reyes que han tenido parte en ella; llamarán las cosas con su proprio nombre, y finalmente serán, respeto de nuestro siglo y deste gran suceso, lo mismo que ahora somos nosotros respeto del siglo de Felipe el Hermoso, y de los Templarios: jueces imparciales, pero severos, únicamente amigos de la verdad, y vengadores inexorables de la inocencia.

No, Mr., no se ven ahora ni partidarios ni enemigos de aquellos religiosos militares; los Reyes que ocupan presentemente los tronos no han heredado las ideas, el odio y las pasiones de los Príncipes destruidores, ni son de sangre o a lo más son parientes laterales y muy remotos que no se interesan absolutamente en la reputación de sus predecesores. ¿No vemos gobernados en la mayor parte de los reinos por casas muy diversas? Y así se dice en el día sin temor lo que se piensa: que Clemente $\mathrm{V}$ fue un simoníaco, que compró la tiara con promesas inicuas, que solamente por temor y en virtud de la sexta de dichas promesas sacrílegas obtuvo Felipe el Hermoso la destrucción de los Templarios conducido de la venganza, de la avaricia y de la crueldad, que el haber hecho quemar vivo al Gran Maestre y haber querido recrear sus ojos con este horrible espectáculo demuestra su barbarie, que el haberlos citado el Gran Maestre a comparecer ante el tribunal de Dios, al Rey dentro de un año y al Papa dentro de cuarenta días, y el haberse verificado puntualmente dentro de esos términos su muerte ${ }^{17}$ parece haber hecho de estos hombres dos ejemplos terribles de la justicia divina, que finalmente las circunstancias de su muerte especialmente de la del Papa, pueden servir de prueba irrefragable. Por lo que mira a los mismos Templarios decimos francamente que este Orden militar habiendo descaecido de su primera institución, abandonándose a una intemperancia que pasó a ser proverbio, y poseyendo muchos bienes sin servir ya de nada a la iglesia ni a los Estados, no podía ser menos de ser el blanco de los Príncipes, sin poderse sostener por algunas virtudes que le mereciesen la protección de la Santa Sede, que por tanto se podía justamente impedir su propagación prohibiéndole el recibir nuevos prosélitos, pero que la mayor parte de las acusaciones contra ellos, siendo desatina-

${ }^{16}$ En la transcripción del ms. uso la ortografía moderna.

${ }_{17}$ El Gran Maestro de la Orden de los Templarios, Jacques de Molay, fue quemado en la hoguera junto a muchos otros hermanos en París, el 18 de marzo de 1314 . Clemente V murió el 20 de abril de 1314 y Felipe IV el 29 de noviembre de 1314. 
das y las obras no bien probadas según la misma bula, su destrucción fue por consiguiente una injusticia palpable, y los suplicios que la siguieron otras tantas crueldades. Así hablamos ahora clara y públicamente.

Es verdad que con esto no reparamos las desgracias de los Templarios, pero les pagamos aquella porción de justicia y de compasión que merecen, y a sus destruidores todo el odio y execración de que son dignos. Miramos los sepulcros de estos con horror, y leemos sus nombres con desprecio, y si sus cenizas pudieran ser sensibles, los haríamos los más viles e infelices de los hombres. Este ejemplo servirá a la instrucción de nuestro siglo, y le hará tocar con la mano lo que él será en los tiempos venideros.

Transportémonos pues a la generación que vivirá en el siglo XXII, generación tan distante de nosotros cuanto nosotros de la del tiempo de los Templarios: no hallaréis en ella ni enemigos ni partidarios de la Compañía de Jesús, sino, cuando más, algunas tristes reliquias de los jansenístas, pero sin reputación, y reducidos a sumo abatimiento y desprecio, como se ven hoy los Albigenses y los Husitas ${ }^{18}$. ¿Habrá aun entonces Parlamentos? ¿Los tronos estarán siempre ocupados de los mismos nombres? Sea de eso lo que fuere, yo veo a aquellos Príncipes y a sus súbditos con unas ideas, con unos designios, y con una política muy diversa de la nuestra. Nuestro siglo que se creía superior a todos los que le precedieron y se llamaba por excelencia el siglo de las luces y de la humanidad, ¿creéis que parecerá tal al siglo XXII?

Pero además de que cada edad se ocupa toda en la admiración de sí propia, ¿por qué privilegio particular deberá ser el siglo XVIII la admiración de todos los otros? ¿Podrá contribuir a eso la causa de los Jesuitas?

No, Mr. (hablemos francamente y sin adulación) no será por excelencia, sino el siglo de los ministros, de las damas, de los filósofos, del jansenismo y de los parlamentos. En la historia deste siglo de la humanidad no se leerán con horror dos asesinatos de Reyes ${ }^{19}$, el destrozo de toda la nobleza de Portugal $^{20}$, la devastación de Polonia ${ }^{21}$, mil sediciones, la des-

\footnotetext{
${ }^{18}$ Hace referencia al movimiento herético de los Albigenses, entre los siglos XII y XIII, en Francia y de los Husitas, en el siglo XV, en Bohemia.

${ }^{19}$ Los dos asesinatos son los de Pedro III de Rusia, víctima de una conjura de Gregorio Orlov, amante de la Reina (que será la famosa emperatriz de Rusia, Catalina II) el 17 de julio de 1762 y el atentado fallido de José I de Portugal el 3 de septiembre de 1758 (el Rey se hizo una herida leve). Más adelante en el texto de esta misma carta, Clavijero usa el término asesinato en una explícita referencia al intento de asesinato del Rey de Portugal ( ¿qqué les parecerá entonces el de Portugal que supone que los Jesuitas fueron cómplices en el asesinato del Rey? ¿No será esto evidentemente falso viendo que ninguno de ellos fue ajusticiado por este parricidio?»).

${ }^{20}$ Después del atentado del soberano fueron ajusticiados el Duque de Aveiro, José de Mascarenhas, El Marqués de Tavora y otros nobles. Todos sus títulos nobiliarios fueron anulados.

${ }^{21}$ Alude a la guerra que Carlos XII de Suecia condujo al inicio del siglo contra Polonia, a la pérdida de su independencia, a la guerra de sucesión polaca (1733-35) y a
} 
trucción de los jesuitas, sus persecuciones, sus prisiones, etc.? Para prueba de sus luces superiores ¿no bastará el saber que adoptó por sus primeros maestros a un Voltaire y a un Rousseau? Que no pudo jamás llegar a certificarse de si había Dios, y si el alma del hombre no era material, y se creyó por lo menos asegurado de que no había Providencia? Que honró con preferencia a una secta, cuyo principio fundamental es que el Dios de toda bondad manda cosas imposibles, y que no quiso jamás permitir que a tal secta se diese el nombre de herejía? Que trató seriamente la cuestión de si el Evangelio es inferior al Alcorán? Que había concebido el designio de no dejar a sus nietos ni Obispos ni Sacerdotes? Que los tribunales laicos se creyeron autorizados para decidir las cuestiones de la Fe, para conferir los bienes eclesiásticos y para administrar los Sacramentos? Que dio más de una vez el espectáculo de Jesucristo llevado violentamente en medio de corchetes, sin avergonzarse de tal indignidad, y aun persiguiendo a los que se oponían? Finalmente que trató de ignorantes y fanáticos a todos los siglos pasados solamente por haber percibido en ellos algunas trazas de religión?

Mas ¿qué hago yo, y a qué fin esta disgresión? No, Mr., no ha sido digresión. Ha sido necesario el dar el retrato de nuestro siglo, porque habiéndose ejecutado en él la abolición de los jesuitas y sus persecuciones, nuestros nietos harán juicio destos sucesos por la idea que tendrán del siglo en que se obraron. Ellos verán que la ruina de la Compañía fue comenzada por los Parlamentos ${ }^{22}$. Este sería como se ve un prejuicio fatal contra ella; pero ellos habrán ya observado que los Parlamentos perseguían de doce años a aquella parte a todos los Sacerdotes católicos, y entre ellos al Arzobispo de la Capital, que tuvieron atrevimiento para decidir de los votos religiosos y para tratar de impío un instituto aprobado por un Concilio ecuménico, y que uniendo la humanidad a las luces desterraron del Reyno a todos aquellos Jesuitas que no quisieron suscribir a un juramento sacrílego, que dentro de breve pasaron tan adelante contra la autoridad soberana que fueron destruidos, y no fueron después restablecidos bajo la condición de contenerse en su deber.

Nuestros nietos verán también las dos casa de Braganza ${ }^{23}$ y de Borbón, cuatro Reyes unidos ${ }^{24}$ para pedir la destrucción de la Compañía. ¡Oh, qué grave presunción contra ella! Sí, Mr., pero no ignorarán ellos lo que fue

su incorporación a Sajonia, también a la repartición de Polonia en 1772, entre Rusia, Prusia y Austria (otras dos reparticiones se darán entre 1793 y 1795).

${ }^{22}$ Hace referencia a los Parlements franceses y en particular a su política entre los años 1752-1764, con la persecución de los Jesuitas llevada a cabo sin tener en cuenta la opinión del Arzobispo de París, el cual era favorable a la Compañía.

${ }^{23}$ El Rey José I (1750-1777) pertenecía a la Casa de Braganza que se había asentado en Portugal en 1640 y que reinó hasta 1807.

${ }^{24}$ Junto a José I de Portugal, el Rey Luis XV de Francia, Carlos III de España y Fernando I (1759-1825)de las dos Sicilias. 
José de Portugal y su ministro Carvallo, que en Francia fue urdida la trama por la Pompadour, mujer sin costumbres, y aun por ventura más sin religión, la cual había ya perseguido a la Iglesia, agotado el erario y trastornado la política, que la España era entonces gobernada por... ${ }^{25}$ Pero, ¿tendrán ellos para con Carlos III aquella parte de respeto que merecía a lo menos su corona, y se acordarán de que él en sí era dulce, piadoso, y equitativo?

Sea lo que fuere destas reflexiones, no hay duda de que nuestros nietos preguntarán por qué estos Príncipes solicitaron la destrucción y los juzgarán rigurosamente sobre su motivo: ¿qué les parecerá entonces el de Portugal que supone que los jesuitas fueron cómplices en el asesinato del Rey? ¿No será esto evidentemente falso viendo que ninguno de ellos fue ajusticiado por este parricidio? Y, fuera de eso ¿no sería un enorme absurdo el pedir por el delito de dos o tres miembros, la supresión de todo el Orden?

Carlos III, rey de España, y consiguientemente el Rey de Nápoles su hijo, protestaron que no declararían jamás su motivo. Esta misma protesta ¿no será en el tribunal de la posteridad una confesión manifiesta de que no tenían motivo alguno legítimo, y no se reirán de semejante protesta?

Finalmente ¿no será una humillación para la Francia el haber declarado que ella no hacía más de seguir las huellas de España, y no será una ignominia para Luis XV el haberse remitido a Carlos III en lo que mira a los motivos? Por lo demás la extraordinaria estimación con que honraron a la Compañía Juan V, Felipe V y Luis el Grande, predecesores inmediatos de los reyes destruidores, ¿no controbalancerá poderosamente a las prevenciones destos últimos? Si yo, Mr., he faltado al respeto debido a los príncipes que hoy reinan, no ha sido sino porque me imaginé trasportado al tiempo de nuestros nietos; que - por lo demás- bien veis que no he dicho aún la mitad de lo que ellos publicarán sin algún miramiento.

Por lo que a ti mira, oh Clemente, yo lo diré todo desde ahora, porque habiéndote sobrevivido, participo ya contra ti de todos los derechos de la posteridad. Es verdad que ella no sabrá tus cábalas y tu conducta desreglada en el claustro; esas son unas menudencias que ella no se dignará de inquirir, pero no podrá ignorar que debiste el capelo a la facción de los jansenistas y la tiara a tus promesas reiteradas de destruir la Compañía; que, después de haber mucho tergiversado por no meterte en un laberinto de dificultades, forzado al fin del temor de ser públicamente deshonrado si

\footnotetext{
${ }^{25}$ Hay una inexplicable reticencia de Clavijero en escribir los nombres de quienes gobernaban la suerte de España. El Primer ministro era el Conde de Aranda (de 1776 a 1773), fue uno de los máximos responsables de la expulsión, aunque puede que Clavijero pensara también en el Fiscal del Consejo de Castilla, José Moñino (futuro Conde de Floridablanca) y en los ministros Manuel Roda y Arrieta, Jerónimo Grimaldi y Pedro Rodríguez de Campomanes.
} 
se hacían imprimir tus promesas simoníacas y por ventura inquietado también sobre tu exaltación, pronunciaste sin proceso alguno preparatorio la sentencia más informe, que entrado después en furor prendiste sin causa alguna a los miembros más distinguidos deste Orden, y que desde este momento habiendo perdido tu alegría natural, el sueño, la salud, y por último el juicio tuviste al cabo de trece meses la muerte más deplorable, dejando en ella el Castillo de S. Ángel lleno de víctimas inocentes tratadas con la mayor inhumanidad, y reservadas por lo menos a perecer todas en la prisión, si algunas no acaban en el patíbulo, que sin embargo de todo lo dicho hiciste milagros por algunos meses hasta que metió la mano la Inquisición ${ }^{26}$. Sí, Clemente, tus milagros particularmente acabarán de instruir a la posteridad de que tu fuiste un Papa, un grande hombre, y un santo de facción. No hablo de tu breve, porque debiendo conservarse este famoso documento de tu conducta, la posteridad juzgará por él de los motivos que te determinaron a la destrucción ${ }^{27}$. Ella, desde luego le opondrá el parecer doctrinal de los Obispos de Francia ${ }^{28}$, todas las bulas de los predecesores, y sobre todo la bula Apostolicum de Clemente XIII, expedida siete años antes ${ }^{29}$. ¿Qué nulidades, qué calumnias no descubrirá evidentemente en este breve? Qué ultrajes del Santo Concilio de Trento, de la Santa Sede, y de tu inmediato predecesor? Finalmente el asunto del Castillo de S. Ángel acabará de decidir irrevocablemente de tu equidad por haber sido la Compañía suprimida por este breve sin proceso preparatorio. Tú hiciste después un proceso criminal contra sus principales miembros en el cual ellos quedaron plenamente justificados. Tu breve pues está lleno de calumnias, y ¿qué motivo tuviste para suprimir este Orden? Tal será, Mr., el lenguaje de todos los que entonces habrán leído algunas páginas de la historia eclesiástica del siglo XVIII, al año de 1773.

Vengamos ahora al pueblo más ignorante. Él no sabrá ni con mucho todas las circunstancias de la destrucción, las amenazas de España, las repugnancias de Clemente, sus remordimientos, su desesperación y su locura consumada. No conocerá los nombres de los cinco Cardenales comi-

\footnotetext{
${ }^{26}$ Alude a los presuntos milagros tras su muerte y condenados muy pronto como inexistentes por parte de la Inquisición.

27 Para una amplia síntesis de la vida y obra de Clemente XIV y sobre las diversas interpretaciones de su papado, ver M. RosA, Clemente XIV en Dizionario biografico degli italiani, Instituto de la Enciclopedia Italiana, Roma, vol. 26, 1982, pp. 343-364.

28 Se trata de la asamblea de obispos de Francia que en noviembre de 1761, bajo la guía del Arzobispo de París, Cristóbal de Beaumont, se declararon por mayoría a favor del mantenimiento de la Compañía. Su parecer fue desatendido por el Parlamento de París, seguido de los Parlamentos de las provincias (ver las notas 9 y 22).

${ }^{29}$ La bula Apostolicum pascendi munus emanada el 7 de enero de 1765 (es decir, ocho, no siete años antes) por el Papa Clemente XIII, inmediatamente después de la supresión francesa, confirmaba la existencia de la Compañía con sus Estatutos tradicionales.
} 
sarios, y mucho menos los de Macedonio y Alfani. Este último, aunque hoy el más famoso, no es al fin otra cosa que el nombre de un malvado efímero, que cuando más no puede vivir arriba de una o dos generaciones, como el de Mandrín ${ }^{30}$, cuarenta o sesenta años en la memoria del pueblo. Si el Carvallo será inmortal en Portugal, eso será porque además de la ruina de los Jesuitas, él ha agotado la más noble sangre desta nación. Mas sin saber todas estas circunstancias, ved aquí, Mr., lo que el más grosero pueblo no ignorará jamás: que hubo Jesuitas, que ellos ocupaban la mayor parte de los Colegios con una reputación extraordinaria, que ellos habían convertido una parte de la India, de la China, y de la América, que los Obispos y los Papas los habían siempre protegido, que ellos fueron enemigos declarados de las herejías de su tiempo, que los jansenistas causaron su ruina, que un franciscano hecho Papa les destruyó sin decir por qué, que su General murió en la prisión, pero habiendo antes protestado su inocencia y la de sus antiguos hermanos en presencia del Santo Viático, que todo el resto de su tropa fue puesta en libertad y declarada inocente, que el Papa destruidor había ya tenido una muerte miserable, que no pudo exponerse en San Pedro su cadáver a la pública veneración, como siempre se había hecho con sus predecesores, porque ya lo habían comido los gusanos. ¿Desearéis saber si el pueblo añadirá si murió envenenado? Sí, Mr., si hubiere entonces jansenistas o franciscanos, porque unos y otros no dejarán jamás de publicarlo: aquellos por continuar sus calumnias contra los Jesuitas, y estos por desvanecer las justas sospechas de la venganza divina contra un Papa de su Orden.

El hombre parcial e instruido ¿no tendrá en efecto alguna cosa que oponer a la Compañía? Sí, tendrá sin duda, pero nada ciertamente que pueda ni con mucho merecer su destrucción. Alguna vanidad en unos hombres de letras, hermanos de los más célebres predicadores, de los sabios teólogos, de los confesores de los Soberanos, de los maestros de los Príncipes, alguna esquivez por la mayor parte respeto de los otros Órdenes religiosos en los cuales no reconocían buena crianza, algún desprecio de aquellos en quienes no hallaban más de ignorancia y desarreglamento, aversión contra muchos en quienes las novedades habían hecho unos progresos casi universales, mucha emulación contra aquellos que - siendo como ellos de mérito- se oponían a sus sistemas teológicos, algunas opiniones singulares y algunas también peligrosas entre una muchedumbre innumerable de sabios, finalmente alguna laxitud en ciertas opiniones morales copiadas de autores extraños y abandonadas a la primera insinuación de la iglesia. No Mr., no tendrá el hombre imparcial otra cosa que reprocharles.

\footnotetext{
${ }^{30}$ Louis Mandrin, bandido francés, nacido en 1764 en Saint Etienne de Saint Georges, gozó de una cierta fama por haber guiado a un grupo de bandidos en unas empresas arriesgadas, incluidos los ataques a las ciudades de Beaume y Autun. Capturado por la delación de una concubina, fue ajusticiado a Valence en 1755.
} 
Los filósofos (pues no hay duda de que los habrá en todo tiempo) les reprocharán también el haber sido muy malos políticos atacando con tanta fuerza la herejía dominante de su siglo que podría arruinarlos, declarándose altamente en favor de la Santa Sede que no querría, por sostenerlos, disgustar a los Soberanos, no condescendiendo a las flaquezas de los Príncipes y de sus damas que no podrían dejar de vengarse cruelmente de ellos, y no acomodándose a las ideas de los ministros que, bajo un gobierno débil, deberían necesariamente aniquilarlos, en una palabra los acusaron de no haber sido en diferentes tiempos y lugares filósofos, jansenistas, parlamentarios, antirealistas, confesores blandos, especialmente en la Corte y religiosos a la moda como todos los demás. Pero todo esto ya se ve que en lugar de servir de reprehensión de la Compañía, será su mayor elogio.

Y ¿se sentirá también entonces la pérdida de la Compañía? Sin duda alguna, y no podrá ser de otra suerte: El pueblo viendo sus Colegios desiertos, la educación de la juventud perdida, sus púlpitos abandonados, y sus iglesias tan brillantes en otro tiempo, medio arruinadas, no preguntará sin cesar ¿porqué la destruyeron?

Leyendo sus libros espirituales, tantos predicadores tan célebres y tan instructivos, las vidas de sus Santos, etc., ¿no se escandalizará de los que la destruyeron? Sabiendo que este orden en espacio de dos siglos tuvo más Mártires en las misiones, convirtió más países bárbaros, y redujo a la Iglesia más herejes que todos juntos los demás Órdenes religiosos, en el mismo tiempo, ¿no se sentirá tentado de decir anatema al que los destruyó?

El sabio viendo las bibliotecas llenas de sus autores y hallando entre ellos lo más excelente de todo género, ¿no se llenará de indignación ante el destruidor, y no dirá en sus trasportes que ningún otro que un franciscano ignorante y sin juicio podría haber sufocado a la Madre de los Petavios, de los Sirmondos, de los Suárez, de los Belarminos ${ }^{31}$, etc.? Los Órdenes mismos émulos en otro tiempo de la Compañía, y que triunfaron en su destrucción, ¿no la llorarán como el único manantial de donde les venía una juventud numerosa y educada en la piedad y en las ciencias? Pero me engaño por ventura en esto, pues en la mayor parte se habrán ya acabado por falta de sujetos, y los que quedaren abandonados a una ignorancia profunda y a una relajación general se alegraran de la misma escasez de sujetos por poder vivir más a su gusto. Por lo que mira a la Santa Sede (pues que infaliblemente subsistirá en todos tiempos a pesar de las faltas de sus pontífices y de todos los esfuerzos de sus enemigos) ella

${ }^{31}$ Clavijero recuerda a algunos grandes teólogos de la Compañía: Denis Petau, nacido en Orleans en 1583, jesuita desde 1605, muerto a París en 1652; Jacques Sirmond, nacido en Roma en 1559, jesuita desde 1576 y muerto en París en 1651; Francisco Suárez, nacido en Granada en 1548, jesuita desde 1564 y muerto en Lisboa en 1617 y Roberto Bellarmino, nacido en Montepulciano en 1542, jesuita desde 1560 y muerto en Roma en 1621. 
sentirá sinceramente la destrucción como su ignominia por haberse ejecutado contra toda equidad, y como su desgracia por haber perdido sus más celosos partidarios, y por hallarse ya entonces privada de la mayor parte de sus prerrogativas. La misma Corte de Roma, los Cardenales y los Prelados reducidos entonces a una estrecha mediocridad, como infaliblemente lo anuncia la presente disposición de las cosas, y acordándose no sin envidia del orgulloso esplendor de sus predecesores, fijarán la época de su decadencia en la destrucción de los jesuitas. ¡Oh, qué pesar tendrán entonces y cuán sincero!

La España en particular ¿no los llorará amargamente cuando habiendo perdido inmensos países en la América, y quizás también todas las riquezas del Perú, se acordará de que el Paraguay fue conquistado, o por mejor decir criado para ella por los Jesuitas que se lo conservaron siempre con gran fidelidad, y le hubieran ásegurado sus posesiones en lo restante de aquella rica parte del mundo? Que la política de no permitir allí Regulares poderosos que pudiesen apaciguar las sediciones con sólo presentarse y conducir armadas con el Crucifijo en la mano, fue la más infeliz de todas las políticas, pues en países tan distintos y tan sujetos a sediciones teniendo necesidad de hombres capaces de sosegarlas para no perder del todo estos países, hubiera sido siempre mejor para el Príncipe mantener este crédito entre las manos de unos Religiosos que por su mismo estado no podían aspirar a la soberanía, y por sus peculiares votos, ni aun podían aceptar alguna dignidad, y cuyos superiores tenía él a su disposición, que no entre las manos de un gobernador que sin temor de Dios ni de los hombres puede usurpar la suprema autoridad y aun se halla tentado de usurparla en efecto por dejarla a sus hijos ${ }^{32}$.

$\mathrm{Si}$ alguna vez la Alemania y la Hungría vuelven a sus antiguos errores, como es de temer por muchas razones, sacudiendo el yugo de la Casa de Lorena le hacen conocer que ya no hay Jesuitas que puedan mantener a los pueblos en la verdadera $\mathrm{Fe}$, y por ella en la obediencia, iqué pesar, aunque infructuoso, no tendrá entonces de haber condescendido por flaqueza a su destrucción, y de haber, por el ruin interés de pillar algunos de sus más ricos Colegios, sacrificado los más celosos defensores de la Reli-

${ }^{32}$ Se refiere a la extinción de las reducciones del Paraguay que a partir de 1609 los Jesuitas habían constituido en los territorios bañados por los ríos Uruguay, Paraná y Paraguay, llegando a convertir y a organizar a los indígenas en una treintena de centros con una población de cerca de cien mil almas, con propiedad y trabajo comunitario. Estas poblaciones habían sabido resistir, aunque con grandes pérdidas, a los numerosos ataques feroces de los paulistas (o mamelucos), mestizos brasileños que andaban a la búsqueda de indios para venderlos como esclavos, y a la constante hostilidad de los encomenderos. España no había sabido defender adecuadamente las reducciones y con la supresión de los Jesuitas había puesto fin al experinento que había suscitado la admiración de tantos en Europa (Montesquieu, Voltaire, d'Alembert y Raynal). 
gión, la cual es la única basa del trono, especialmente en aquellas regiones, y de haber profanado todos los testamentos de los Emperadores de la Casa de Austria, en los cuales nada encargaban tanto a sus sucesores, cuanto la protección de la Compañía de Jesús!

La posteridad no dejará de hacer esta triste reflexión, que una Reina, último renuevo de aquella famosa Casa, destruyendo antes de morir todas las más magníficas y santas fundaciones de sus antepasados, parece que pretendió sepultar con las últimas gotas de su sangre la más bella parte de su gloria ${ }^{33}$.

Pero, sobre todo, ¿qué dirá la posteridad viendo que dos Soberanos herejes han sido los únicos en salvar las reliquias de la Compañía: Federico y Catalina? El uno, Rey filósofo, y el mayor general de su siglo protesta que quiere conservar a los jesuitas para la educación de la juventud en sus Estados, y para la conservación de la $\mathrm{Fe}$ romana; porque habiendo jurado de no hacer mutación alguna en ella en la Silesia y en la Polonia y habiéndole asegurado los Obispos católicos que estos hombres son los mejores por no decir los únicos obreros evangélicos en aquellas regiones, no solamente quiere servirse de ellos para ese fin, sino también guardarlos como un almácigo «para que» - según él afirma - «en cesando el fanatismo acudan a él los príncipes católicos a proveerse, y entonces se los haga pagar bien caros».

Catarina, Emperatriz de las Rusias, después de haber llenado de terror el Mediterráneo con sus flotas y de haber hecho temblar al Turco en su serrallo, habiéndose apoderado de una parte de la Polonia, en donde halló la Religión romana que prometió conservar, y en donde no halló otros que los Jesuitas que pudiesen felicitarle este designio, no quiso consentir a su destrucción, y aun les ha fundado nuevas misiones. En los tiempos venideros será todo esto para gloria, o para ignominia de la Compañía. Sería sin duda para su ignominia si el haber sido conservada hubiera sido por otro motivo, que por el de la conservación de la Fe ortodoxa, y el de la educación de la juventud. Tampoco sería para ella de mucho honor el haber sido conservada aun a ese fin por dos soberanos de corto mérito; pero será sin contradicción el colmo de su gloria el haber sido conservada únicamente a título de mérito por el bien de la $\mathrm{Fe}$ y porque no se hallaron otros sujetos que pudiesen reemplazarla, por los dos mayores Príncipes de la Asia y de la Europa, y sin embargo de los prejuicios de una Religión contraria, así como será única gloria destos dos grandes Monarcas el no haber consentido en la destrucción por motivos ignorados o por el de un vil interés,

\footnotetext{
${ }^{33}$ Acusa de culpable de debilidad a María Teresa de Austria (1717-1780), archiduquesa de Austria, reina de Hungría, emperatriz de Alemania, esposa desde 1736 de Francisco I de Lorena (nombrado Emperador en 1745) que pese a ser una ferviente católica, y tras haberse declarado inicialmente como favorable a los Jesuitas, favoreció la supresión de la Compañía con su constante proclamación de indiferencia ante el problema.
} 
y el haber protegido el mérito aun en hombres de religión diversa de la suya.

Hasta aquí, Mr., he hablado siempre en la suposición de que jamás fuesen restablecidos los jesuitas como en efecto no hay la menor apariencia de que jamás lo hayan de ser; pero si alguna vez llegan a reponerse, ¿qué dirá la posteridad de su destrucción y de sus destruidores? Estos tiemblan ya solamente de imaginarlo, y se creerían desde luego perdidos sin remedio en la opinión de las edades futuras.

$\mathrm{Y}$ vos, Mr., ¿qué pensáis? Yo de mi parte dudo mucho que sea justo su sentimiento; antes por el contrario si la Compañía resucitase, ellos podrían estar seguros de tener siempre un poderoso partido, y si ella quedase extinta, no tendrían ciertamente pasado cierto tiempo ni un solo apologista. Sí, Mr., o si no decidme ¿los Jesuitas restablecidos serían, como han sido, sabios, celosos y laboriosos? Pues no podría faltarles jamás una gran muchedumbre de enemigos, de envidiosos y de murmuradores. Los filósofos, los herejes, los libertinos, y la mayor parte de los religiosos repetirían entonces sin cesar que fue muy justa la destrucción, y que se cometió un grande error en restablecerlos, en una palabra que Clemente XIV fue infinitamente superior a X X. He aquí infinitos apologistas de la destrucción, porque no tratamos ahora de pesar los sufragios, sino hablamos solamente del número, y no ignoráis que el mayor número nunca es, por nuestra desgracia, de hombres de bien y cuerdos. Serán pues los destruidores siempre aplaudidos y de todas partes.

Si los Jesuitas hubieren degenerado, y no sirvieren ya a la Iglesia, ni al Estado, entonces serán más generales los clamores de haberse cometido un gran yerro en su restablecimiento, y de haber sido muy justa su destrucción, porque ¿quién habrá que sepa distinguir los Jesuitas que entonces vivían envilecidos, de los que en otro tiempo existieron? Serán pues universalmente aplaudidos los agentes de la destrucción, y tendrán de su parte en esta segunda hipótesis aun a los hombres de bien, a lo menos a aquellos que no reflexionan. Por el contrario si se supone eterna la destrucción, después desta generación de cábalas, y del abatimiento de los jansenistas, los espíritus volviendo insensiblemente a su equilibrio no percebirán algunas consecuencias ventajosas de la destrucción, sino muy funestas, no hallando en el primer proceso más de ilegitimidad, injusticia y crueldad.

Se preguntará incesantemente por qué fueron abolidos los Jesuitas; será siempre censurado el modo con que se ejecutó la destrucción y no habrá quien citando nuestro siglo a su tribunal no condene sin respeto alguno a los ministros que la sugirieron, a los Príncipes que la pidieron, a los que a ella consintieron, y sobre todo al Papa que la consumó, a los comisarios que la ejecutaron, al Sacro Colegio que no se opuso, a aquella chusma de religiosos y eclesiásticos fanáticos que la aplaudieron, y al pueblo simple 
que se contentó de murmurar entre dientes. ¿Pretendo yo por ventura que se excitasen sediciones? No se trata aquí de mí; solamente afirmo que la posteridad reprochará a los pueblos el no haberse lamentado a las claras, y el no haber alzado el grito.

Reflexionad, Mr., atentamente sobre todo lo dicho, y ved si he acertado a adivinar el futuro. Yo no soy como se dice, hijo de profeta, pero ¿son menester por ventura luces superiores para ver acontecimientos tan naturales, y de los cuales podemos seguramente juzgar por los sucesos pasados?

Tengo el honor de ser vuestro. 